\title{
The Issuance of Series-1996 \$100 Federal Reserve Notes: Goals, Strategy, and Likely Results
}

Theodore E. Allison and Rosanna S. Pianalto, of the Office of Board Members, prepared this article.

In March 1996, the Federal Reserve began issuing series-1996 \$100 Federal Reserve notes. Culminating a cooperative effort by the U.S. Department of the Treasury and the Federal Reserve System that dated from the 1980s, the series-1996 note was the first major design change in U.S. currency in sixty-six years. The new note was developed to provide better protection for users of U.S. currency against the growing threat of counterfeiting, especially that posed by increasingly affordable and capable color scanning and printing systems.

The Federal Reserve's strategy for issuing newly designed $\$ 100$ notes involves neither a recall of notes with the old design nor a deadline for exchanging them. The Federal Reserve is, however, withdrawing pre-series-1996 notes when they are deposited at Federal Reserve Banks.

\section{THE CHOICE OF AN ISSUING STRATEGY FOR NEWLY DESIGNED CURRENCY NOTES}

Central banks have a range of available strategies for introducing new currency designs, and no single strategy is appropriate in every circumstance. In general, when issuing new currency designs, central banks wish to minimize the inconvenience to the public, to minimize their own costs, and to achieve a timely replacement of old-design notes. These objectives are seldom mutually attainable, however, so choosing a strategy requires the central bank to assess the tradeoffs carefully, especially between convenience to the public and timeliness of the replacement of old-design notes.

At one extreme, an issuing authority might establish a relatively brief period-perhaps as short as a few months-during which the public would have to exchange notes of the old-design series for those of the new. After the period ended, old-design notes might no longer be valid or might be valid only at the central bank. This option could be quite inconvenient for the public and relatively costly to the central bank because the old-design notes would be taken out of circulation before the end of their otherwise useful life. But it might be considered desirable if a prompt withdrawal of old-design notes could avert what otherwise might have been a serious counterfeiting problem.

At the other extreme, an issuing authority might replace old-design notes only as they became unfit (that is, too soiled) for further circulation. This option would likely be the least inconvenient to the public and the least costly to the central bank; but under certain conditions it might be unacceptable because it would not achieve replacement quickly enough.

Assessing the impact of a strategy on public convenience requires knowledge of where, by whom, and for what purposes the currency is held. Whether the timeliness of the likely replacement of old-design notes resulting from a potential strategy is acceptable depends on two things: the nature of the counterfeiting threat to the old-design notes and the pace at which old-design notes may be expected to be deposited at the central bank under various strategies.

\section{FEDERAL RESERVE GOALS AND STRATEGY FOR INTRODUCING SERIES-1996\$100 NOTES}

In developing plans for issuing series-1996 \$100 notes, the Federal Reserve likewise was guided by the goals of (1) imposing as little disruption as possible on business firms and households, both within and outside the United States, and (2) carrying out the introduction so as to achieve an expeditious substitution of new-design notes for the pre-series-1996 notes. In pursuing those objectives, the Federal Reserve adopted a strategy for issuing the newdesign $\$ 100$ notes that has several components:

- There was to be no recall of pre-series-1996 $\$ 100$ notes, no requirement that the public exchange old-design $\$ 100$ notes for new-design notes, and, for any holder who might wish to make such an exchange, no time limit for doing so. No U.S. currency note has ever been recalled from circulation or invalidated. All genuine $\$ 100$ notes now in circula- 


\section{Two Alternative Strategies for Issuing New Currency Series}

To provide perspective on the strategy adopted by the Federal Reserve for issuing the 1996 series \$100 noteswhich, in brief, is to permit notes of previous series to remain in circulation, as legal tender, for as long as holders are willing to use them but to withdraw and replace previous-series $\$ 100$ notes at the Federal Reserve at the first opportunity-here are the issuing policies used recently by two major European central banks: the Bank of England and the German Bundesbank. Each bank has issued a new design for the highest-denomination note in its currency within the last few years.

\section{England}

The Bank of England introduced a redesigned $£ 50$ note on April 20, 1994 (as part of a series of new designs that began in 1990 with a new $£ 5$ note). The public was informed that the old series of $£ 50$ notes would remain legal tender for some time but that eventually legal tender status would be withdrawn. In fact, previous-series $£ 50$ notes and newdesign $£ 50$ notes circulated together for about twenty-nine months. During that period, the Bank of England withdrew previous-series notes as they were returned to the Bank and replaced them with new-design notes, achieving a replacement of about 80 percent of the old series. In early 1996, the Bank announced that, effective September 20, 1996, $£ 50$ notes of the previous series would no longer have the status of legal tender. However, the "promise to pay the bearer the sum of ..." on Bank of England notes stands good for all time, and the Bank will pay out in notes of the series then current the face value of any genuine Bank of England note, no matter how old.

\section{Germany}

The Bundesbank introduced a newly designed 100deutchmark note in October 1990 (as well as a new DM200 note at the same time and newly designed DM10, DM20, and DM50 notes in 1991 and 1992). In an approach similar to that used by the Bank of England, the Bundesbank informed the public in advance that previous-series notes would remain legal tender for some time but would eventually be recalled from circulation. Previous-series notes were withdrawn by the Land Central Banks (whose functions are similar to those of Federal Reserve Banks in the United States) and replaced with new-design notes as they were deposited by commercial banks. By September 1992, newseries DM100 notes accounted for 85 percent of the total DM100 circulation (although lower denominations had not at that point reached the same level of replacement). In June 1994, the Bundesbank announced a recall of the old-series notes of all denominations. Notes of the previous series still retain their value and may be exchanged at the Bundesbank free of charge for notes of the new series. tion will remain legal tender and will be accepted for deposit at full face value at all Federal Reserve Banks.

- The Federal Reserve has taken steps to ensure the availability of an adequate supply of series-1996 $\$ 100$ notes worldwide, primarily through commercial banks that are active buyers and sellers of currency.

- The Treasury Department, with the participation of the Federal Reserve and of U.S. embassies abroad, has provided substantial information to the public about the introduction of the new-design notes wherever Federal Reserve notes are used to a significant extent. This information has been disseminated partly to reassure holders of old-design $\$ 100$ s that those notes will remain valid and to discourage them from exchanging the notes unnecessarily rapidly.

- The Federal Reserve is withdrawing pre-series$1996 \$ 100$ notes as soon as they are deposited at Federal Reserve Banks by depository institutions and replacing them with series-1996 \$100 notes.

- The Federal Reserve has promised depository institutions that it will process all international deposits of $\$ 100$ notes within two business days and all domestic deposits within five business days of receipt in order to be able to report promptly on any counterfeit notes that the deposits may contain. The Federal Reserve detects virtually all counterfeit notes in deposits and charges the institution for them.

- Soon after introducing the series-1996 \$100 note in March 1996, the Federal Reserve began contacting larger depository institutions to encourage them to deposit their entire inventories of $\$ 100$ notes at the Federal Reserve in order to replace them with inventories of the new-design notes. This process is likely to continue and to be gradually extended to smaller depository institutions. Depository institutions are not required to sort their $\$ 100$-note deposits according to series, nor are they prohibited from paying pre-series1996 \$100 notes to customers.

As previously indicated, various alternatives for introducing the new-design $\$ 100$ notes were available to the Federal Reserve (see box "Two Alternative Strategies for Issuing New Currency Series"). This particular strategy was chosen in consideration of the quantity of $\$ 100$ notes in circulation, where and for what purposes they are held, the nature of the 
counterfeiting threat, and the pace at which the strategy could be expected to achieve a timely replacement of old-design notes.

\section{THE GROWTH AND LOCATION OF U.S. CURRENCY IN CIRCULATION}

The value of Federal Reserve notes in circulation has grown rapidly in the past twenty-five years and especially since 1990 (chart 1). ${ }^{1}$ That growth has been fueled in large part by a strong demand for $\$ 100$ notes, which also has been especially robust since 1990. By the end of 1995, just before the introduction of series-1996 \$100 notes, the value of Federal Reserve notes in circulation had reached about $\$ 400$ billion and that of $\$ 100$ notes about $\$ 240$ billion.

The growth both of total Federal Reserve notes and of $\$ 100$ notes has been propelled by growth in the use of U.S. currency outside the United States. The Board's staff estimates that, by 1995, the proportion of the growth in Federal Reserve notes outstanding that was accounted for by international flows had climbed to 74 percent (chart 2). ${ }^{2}$ It also estimates that as much as $\$ 250$ billion, or more than 60 percent, of the approximately $\$ 400$ billion of U.S. currency in circulation at the end of 1995 was held outside the United States and that as much as $\$ 160$ billion, or two-thirds, of the $\$ 240$ billion of $\$ 100$ notes in circulation may have been held abroad.

The U.S. currency that is held outside the United States appears to be quite dispersed. Data for origins of deposits and destinations of withdrawals of Federal Reserve notes at Reserve Banks since 1990 indicate that U.S. currency is used to a significant extent in parts of Latin America, in parts of the former Soviet Union, elsewhere in Eastern Europe, in parts of the Middle East and of North Africa, and in several countries in Southeast Asia.

1. In this article, the terms "U.S. currency" and "Federal Reserve notes" are used synonymously even though a small proportion of the former consists of coins and of banknotes other than Federal Reserve notes. The terms "U.S. currency in circulation" and "Federal Reserve notes in circulation" refer to Federal Reserve notes held outside the Federal Reserve System - that is, including amounts held by commercial banks.

2. For more detail on the use of U.S. currency outside the United States and on the Board staff's estimates of the amount of such currency, see Richard D. Porter and Ruth A. Judson, "The Location of U.S. Currency: How Much Is Abroad?" Federal Reserve Bulletin, vol. 82 (October 1996), pp. 883-903. For an analytical treatment of the impact of the new $\$ 100$ notes on counterfeiting, see Edward J. Green and Warren E. Weber, "Will the New \$100 Bill Decrease Counterfeiting," Working Paper 571 (Federal Reserve Bank of Minneapolis, September 1996).
1. Value of Federal Reserve notes in circulation, 1970-96

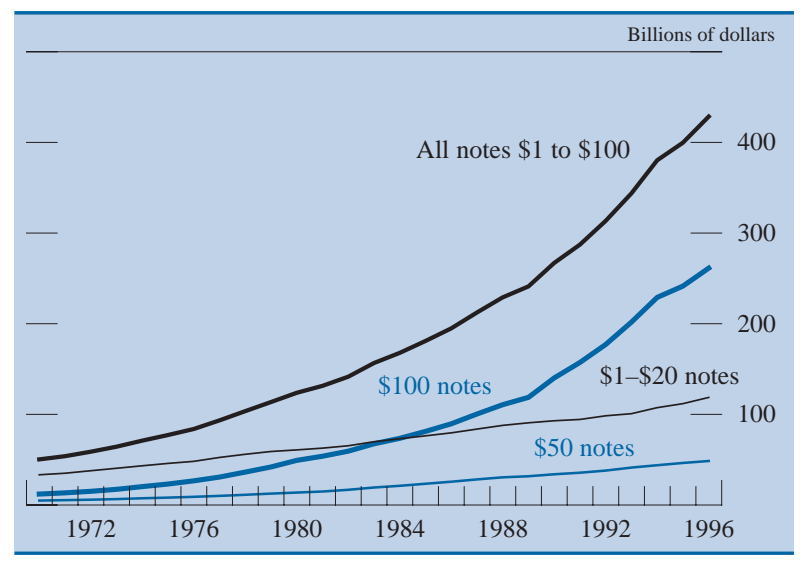

"Dollarization" of economies outside the United States is not a new phenomenon, but it has become significantly more common in the 1990s with the liberalization and democratization of economic systems around the globe. The process of so changing the economic system, which typically fosters new business firms, more business and personal transactions, and new household saving within the nation, has at the same time often been accompanied by high rates of inflation and inadequately developed financial sectors. Rapid inflation makes domestic currency an unattractive medium for saving and transacting and, at the extreme, impractical even as a unit of account. Consequently, the demand in these nations for "hard" currencies, especially dollars in many cases, has been strong (see box, "How Federal Reserve Notes Enter Circulation in a Country outside the United States").

2. Net international payments of U.S. currency as a proportion of annual growth in total circulation of notes, 1981-95

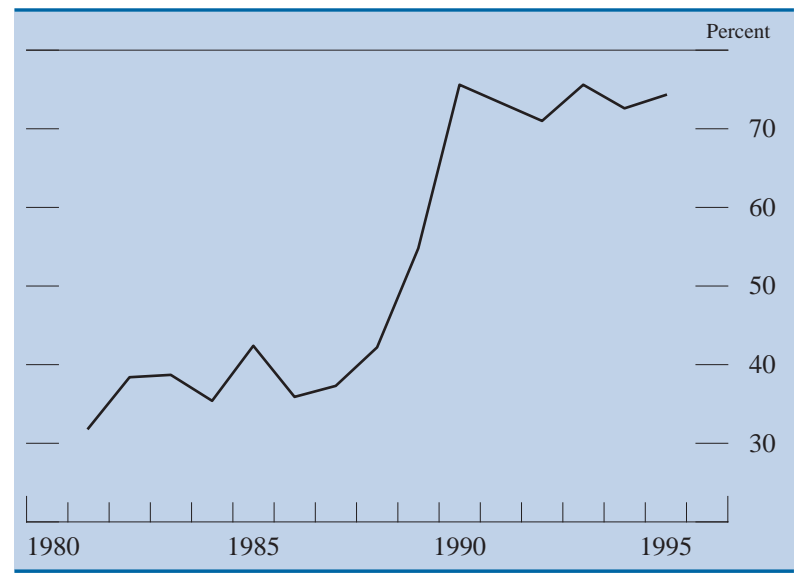




\section{How Federal Reserve Notes Enter Circulation in a Country outside the United States}

The following scenario concerning the mythical emerging nation of Costa Blancastan illustrates the usual process by which Federal Reserve notes enter circulation in another country. The scenario begins with the ABC Bank in Costa Blancastan anticipating a demand from its customers for $\$ 1$ million of $\$ 100$ Federal Reserve notes.

\section{Day 1}

Using its Costa Blancastani currency resources, $\mathrm{ABC}$ Bank, in the foreign exchange market in Costa Blancastan, buys a dollar balance at a major western bank, DEF Bank, in the amount of about $\$ 1,005,000$. ABC Bank now calls several banks that it knows are regular buyers and sellers of Federal Reserve notes and asks for offers on $\$ 1$ million in $\$ 100$ banknotes to be delivered to its office in Costa Blancastan three days later. After receiving offers, $\mathrm{ABC}$ Bank decides to buy from XYZ Bank, which is based in, say, Zurich, Switzerland, and has a branch in New York, which branch in turn has a deposit account at the Federal Reserve Bank of New York (FR Bank of New York). XYZ Bank has quoted a price of $\$ 100.50$ per $\$ 100$ notethat is, the face value of the notes plus 0.5 percent of the value for handling. As is customary in such transactions, the handling fee covers transportation to $\mathrm{ABC}$ Bank's facility. ABC Bank orders a transfer of $\$ 1,005,000$ from its deposit account at DEF Bank to its account at XYZ Bank. XYZ Bank orders \$1 million in $\$ 100$ Federal Reserve notes from FR Bank of New York for pickup the following day.

\section{Day 2}

On the second day, XYZ Bank's armored carrier picks up $\$ 1$ million of $\$ 100$ Federal Reserve notes at FR Bank of New York and sends the package by overnight air shipment to XYZ Bank in Zurich. FR Bank of New York charges XYZ Bank's deposit account in the amount of $\$ 1$ million.

\section{Day 3}

The \$1 million in \$100 Federal Reserve notes arrives at XYZ Bank on the morning of the third day. XYZ Bank verifies the quantity and forwards the shipment to Costa Blancastan, again by overnight air. (In practice, XYZ Bank may have obtained considerably more than $\$ 1$ million of Federal Reserve notes from FR Bank of New York in order to meet obligations to various customers, like ABC Bank, that are located in a variety of countries. These Federal Reserve notes would be repackaged into smaller lots at the XYZ Bank's facility in Zurich. XYZ Bank may also have purchased Federal Reserve notes from other customers, also located in various countries, which it would have shipped to FR Bank of New York for credit to its account there.)

\section{Day 4}

In the morning of the fourth day the Federal Reserve notes arrive in Costa Blancastan, where XYZ Bank has arranged for their delivery by armored carrier to $\mathrm{ABC}$ Bank. Upon receiving and verifying the notes, $\mathrm{ABC}$ Bank places them on sale at its offices, anticipating selling them at a price, in Costa Blancastani currency, that will exceed their cost.

In macroeconomic terms, the description above presents the transactions of an individual Costa Blancastani financial institution and leaves the international accounts of Costa Blancastan "out of balance." In fact, there must have been an ultimate counter party to ABC Bank's original foreign exchange transaction who either was purchasing an exported good from Costa Blancastan (for example, a commodity or a manufactured good) or was making a capital investment in that nation (for example, buying an ownership interest in a firm there) and therefore needed to acquire, using a dollar balance, a deposit balance denominated in Costa Blancastani currency. In the final macroeconomic analysis, then, the citizens (including the central bank) of Costa Blancastan must have parted with $\$ 1$ million worth of commodities or manufactured goods, or have otherwise reduced their net foreign asset position, to have acquired $\$ 1$ million of U.S. currency.
Moreover, our research suggests that, within many dollarized countries, Federal Reserve notes are widely held and used both by households and by business firms of all sizes. Households use U.S. currency for short-term and long-term saving and in transactions for a variety of higher-priced goods and services, such as consumer durables and real estate.
Businesses are likely to find U.S. currency useful not only as a hedge against local-currency inflation but also for settling firm-to-firm transactions where clearing and settlement systems for other payment media (such as checks and electronic transfers) are not well developed or where the existence of more than one local currency would unduly complicate a transac- 


\section{How Federal Reserve Notes in Circulation Provide a Benefit to Taxpayers}

Depository institutions keep deposit accounts at one of the twelve Federal Reserve Banks (collectively, the Federal Reserve), both to satisfy their legal reserve requirements (reserve balances) and to cover charges and credits arising from payments made by and to the depository institutions that are cleared through the Federal Reserve (clearing balances). A depository institution may obtain Federal Reserve notes from the Federal Reserve in exchange for a deduction from its deposit account and may deposit Federal Reserve notes at the Federal Reserve in exchange for a credit to its deposit account.

Here is an abbreviated balance sheet of the Federal Reserve for December 31, 1996 (amounts are in billions of dollars):

\section{Federal Reserve Banks}

$\begin{array}{lrl}\text { U.S. government securities } & 420 & \text { Depository institution } \\ \text { Other securities } & 20 & \text { deposits } \\ \text { Other assets } & 20 & \begin{array}{l}\text { Federal Reserve notes } \\ \text { in circulation } \\ \end{array} \\ & \begin{array}{l}\text { Other deposits } \\ \text { Capital accounts }\end{array} \\ & \overline{460} & \end{array}$

Let's say that customers of depository institutions increase their demand for Federal Reserve notes by $\$ 1$ billion. Depository institutions would obtain that quantity of Federal Reserve notes from the Federal Reserve against a $\$ 1$ billion charge to their deposit accounts. The first round of accounting entries for the Federal Reserve would show an increase in Federal Reserve notes in circulation and a decrease in depository institution deposits, both of \$1 billion:

\section{Federal Reserve Banks}

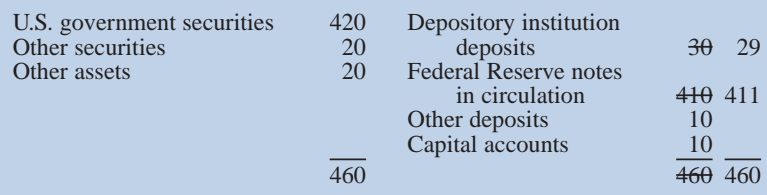

This transaction would, however, leave depository institutions, in the aggregate, with a $\$ 1$ billion deficiency in reserve balances or clearing balances, requirements for both of which are fixed in the short run. The result, without an offsetting action by the Federal Reserve, would be a tightening of conditions in the federal funds market and an increase in the federal funds rate. That result would be inconsistent with the Federal Reserve's monetary policy objectives, which are expressed in the very short run in terms of a particular value for the federal funds rate. To prevent that result, and thus preserve existing conditions in the federal funds market, the Federal Reserve would purchase \$1 billion of securities (through an open market operation) in order to provide $\$ 1$ billion of new reserves. The Federal Reserve's resulting balance sheet position would show liabilities for depository institution deposits restored to the original level; liabilities for Federal Reserve notes in circulation up \$1 billion; and holdings of U.S. government securities up $\$ 1$ billion:

\section{Federal Reserve Banks}

\section{U.S. government securities} Other securities
Other assets 9 411

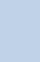

tion, as in cross-border transactions within the former Soviet Union.

Quite apart from the phenomenon of the dollarized countries, U.S. currency is widely used and accepted internationally for business and leisure travel as well as for salaries of and remittances by migrant workers of many nationalities. Federal Reserve notes are also a preferred medium for holding stores of wealth in some countries in which gold once played a large role for that purpose.

The extent of the worldwide dispersion of its currency notes bestows important benefits on the
United States, not least of which is that it provides significant revenue-perhaps as much as $\$ 15$ billion per year-to the U.S. Treasury (see box, "How Federal Reserve Notes in Circulation Provide a Benefit to Taxpayers"). However, it also imposes certain obligations: Care must be taken not to disrupt the lives and livelihoods of the hundreds of millions of households and business firms outside the United States that have chosen to hold a significant portion of their wealth or working capital in U.S. currency.

In view of the widely dispersed holdings of Federal Reserve notes throughout the world and the consider- 
able extent to which they are used by households for saving and by business firms for working capital, it seems appropriate that the Federal Reserve's issuing strategy would seek to minimize the inconvenience to holders of $\$ 100$ notes. A more aggressive strategy could have been significantly disruptive to holders of those notes and possibly even have raised questions about the long-term desirability of holding U.S. currency notes as a vehicle for transactions and saving.

Another question is whether the strategy will achieve an acceptably timely replacement of olddesign notes. The answer depends in part on an assessment of the counterfeiting threat and in part on the pace at which Federal Reserve notes can be expected to be deposited at Federal Reserve Banks.

\section{THE COUNTERFEITING THREAT TO U.S. CURRENCY}

The worldwide acceptance of U.S. currency has made it a favorite target of counterfeiters. Indeed, Federal Reserve notes are under attack from various sources, most of them located outside the United States, and various reprographic methods, ranging from home scanners and printers to commercial-type printing presses.

Fortunately, thanks to good law enforcement, a generally good design, and, especially, a watchful public, the currency of the United States is relatively free from counterfeits, both domestically and internationally. The current value of counterfeits passed on the public in the United States is on the order of $\$ 30$ million per year, which is less than 15 cents per U.S. citizen. ${ }^{3}$ Thus counterfeiting, though the cost of which is too high in principle, has no discernible effect on the U.S. economy. The successful passing of counterfeit U.S. currency outside the United States appears not to be appreciably different from that within the United States, in relation to the quantity of genuine notes in circulation. ${ }^{4}$

3. Counterfeits "passed" are those that are detected in circulation, having been successfully used in a transaction. Passed counterfeits do not include those that are seized by law enforcement agencies before having entered circulation.

4. More information about the security of U.S. currency against counterfeiting may be found in "Statement by Theodore E. Allison, Assistant to the Board, Board of Governors of the Federal Reserve System, before the Subcommittee on General Oversight and Investigations of the Committee on Banking and Financial Services, U.S. House of Representatives, February 27, 1996," Federal Reserve Bulletin, vol. 82 (April 1996), pp. 320-22; and "Statement by Edward W. Kelley, Jr., Member, Board of Governors of the Federal Reserve System, before the Committee on Banking, Finance and Urban Affairs, U.S. House of Representatives, July 13, 1994" Federal Reserve Bulletin, vol. 80 (September 1994), pp. 789-91.
Moreover, the Federal Reserve is confident that it has a reasonably clear and up-to-date picture of the extent of counterfeiting of U.S. currency, both domestically and abroad, so that any material change would become evident fairly quickly. The clarity and timeliness of the Federal Reserve's picture of the counterfeiting situation are provided by, first, the large proportion of outstanding notes that the Federal Reserve Banks receive from circulation each year and are therefore able to examine and, second, the ability of note-verifying equipment and the staff at Federal Reserve Banks to accurately distinguish between genuine and counterfeit notes.

Counterfeits in $\$ 100$ deposits at the Federal Reserve during 1995 amounted to 0.0075 percent. That is, the Federal Reserve Banks found, on average, seventy-five counterfeit $\$ 100$ notes in every one million $\$ 100$ notes processed. In value, counterfeits amounted to $\$ 6.9$ million in $\$ 100$ receipts of $\$ 93$ billion. For 1995 deposits at Federal Reserve Banks that originated outside the United States, the rate of detection of counterfeit $\$ 100$ notes was lower than the overall rate, at fifty-four per million.

The seventy-five-per-million detection rate of $\$ 100$ counterfeits in deposits at Federal Reserve Banks in 1995 was slightly lower than the rate in 1994, which was eighty per million, and up slightly from the seventy-one-per-million rate in 1991.

Although Federal Reserve notes are relatively free from counterfeiting now, the security features of the pre-1996 design were considered inadequate for dealing with the emerging counterfeiting threats, especially those from computer-based scanners, printers, and copiers that will be available to large numbers of people and that will require little skill to operate. That threat, however, is not yet critical. Indeed, systems that use scanners-driven either by copiers or by computers-though becoming gradually better and cheaper, still account for a small percentage (7 percent) of the total $\$ 30$ million in counterfeits passed on the public in the United States. ${ }^{5}$

Clearly, neither the current counterfeiting situation nor the likely threat over the coming several years argues for causing significant inconvenience or disruption to the public in order to remove pre-series1996 notes from circulation. Nevertheless, the design features of series-1996 notes provide the public with better security against the future threat of counterfeiting by scanner-based tools and other methods, and old-design notes will, therefore, need to be replaced over time. The rapidity of the replacement of old-

5. Fiscal year 1995. Data provided by Counterfeit Division, U.S. Secret Service. 
design notes that the Federal Reserve's issuing strategy will achieve depends on the frequency with which $\$ 100$ notes are deposited at Federal Reserve Banks and thereby can be withdrawn and replaced.

\section{RAPIDITY OF REPLACEMENT OF PRE-1996 $\$ 100$ NOTES AT FEDERAL RESERVE BANKS}

The Federal Reserve's experience in introducing series-1990 \$100 notes can provide a basis for evaluating the rapidity of replacement of pre-1996 $\$ 100$ notes with those of series-1996. The issuance of series-1990 notes began in August 1991 and concluded in March 1996 with the introduction of their successors. In issuing series-1990 notes, the Federal Reserve followed essentially the same procedure that was just described for the 1996 series.

The extent of replacement of pre-1990 notes with series-1990 notes is indicated by the proportion of $\$ 100$ notes in circulation at any point that is accounted for by notes of the new design. The System's accounting records allow the Federal Reserve to calculate this measure with high precision. ${ }^{6}$ The proportion of $\$ 100$ notes in worldwide circulation that was accounted for by series-1990 notes rose continuously after the initial introduction, reaching 50 percent in August 1993 (twenty-four months after initial introduction) and 75 percent at the end of 1995 (fifty-two months after initial introduction) (see charts 3 and 4).

6. Because the denominator of the fraction just described is the cumulative total of all $\$ 100$ Federal Reserve notes issued in the past and because some of those notes have been lost, destroyed, or taken permanently out of circulation for numismatic purposes, the accounting approach slightly understates the true extent of replacement.

3. Issuance of series-1990 $\$ 100$ notes: Proportion of worldwide circulation and of Federal Reserve receipts of all \$100 notes, 1991-96

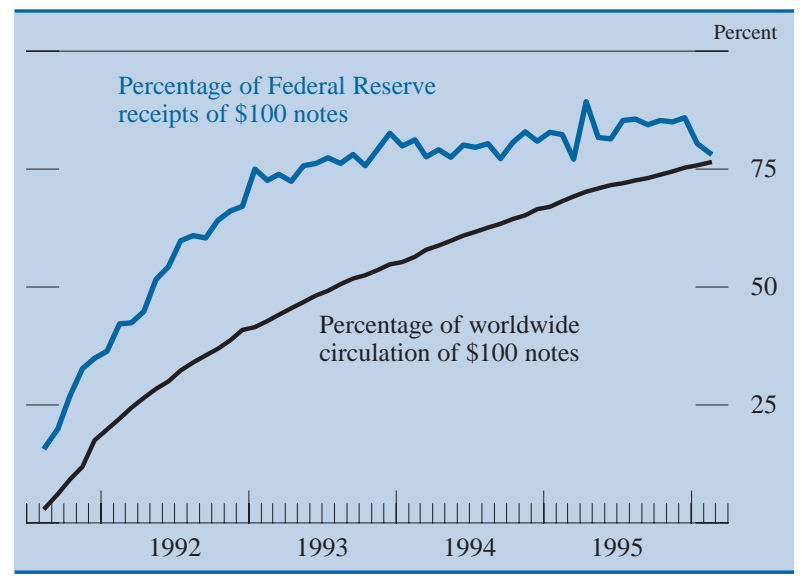

4. Issuance of series-1990 and series-1996 \$100 notes: Proportion of worldwide circulation and of Federal Reserve receipts of all $\$ 100$ notes

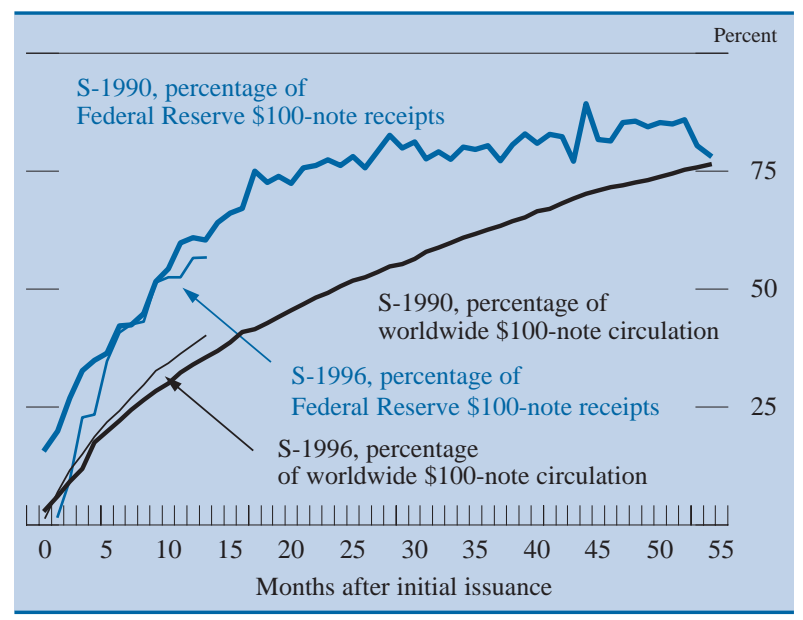

To estimate the rate of replacement of pre-1990 $\$ 100$ notes within the United States, one can look at the deposits of $\$ 100$ notes at Federal Reserve Banks. These deposits in any period represent the $\$ 100$ notes that were taken in by depository institutions from their customers and were considered to be in excess of the institutions' needs in that period; therefore, they are assumed to be a good indicator of the general circulation of such notes within the United States. In the period following the introduction of series-1990 $\$ 100$ notes, the proportion of these notes in $\$ 100$ receipts at Federal Reserve Banks rose steadily and more quickly than the proportion for total circulation. Series-1990 \$100 notes accounted for more than 75 percent of such deposit receipts by August 1993 (the twenty-four-month point) and more than 85 percent by the end of 1995 (after fifty-two months).

The extensive replacement of pre-1990 \$100 notes within only $4 \frac{1}{3}$ years was made possible by a large volume of $\$ 100$ deposits by depository institutions at Federal Reserve Banks. Throughout the period, annual Reserve Bank receipts of $\$ 100$ notes consistently amounted to more than 30 percent of the average worldwide circulation of $\$ 100$ notes. During 1994 and 1995, receipts at Reserve Banks identified by customers as coming from outside the United States amounted to about 10 percent and 15 percent, respectively, of the amounts estimated to be in circulation outside the country during those periods; the corresponding ratios for $\$ 100$ deposits from domestic sources were 80 percent and 90 percent. Thus, the propensity of depository institutions to make frequent deposits at the Federal Reserve of $\$ 100$ notes considered excess to their needs-on average, more than 
30 percent of the total circulation of $\$ 100$ notes each year and more than 80 percent of the domestically circulating \$100 notes-gives the Federal Reserve an opportunity to remove a great many notes of the prior series and replace them with new-series notes, with no disruption to the public.

For the issuance of series-1996 \$100 notes, thirteen months of available data are presented in chart 4. At the end of April 1997, series-1996 \$100 notes composed 40.1 percent of all $\$ 100$ notes in worldwide circulation, well ahead of the 35.5 percent level achieved after thirteen full months in the series-1990 introduction. At the same point, series-1996 notes composed 56.7 percent of the domestic circulation of $\$ 100$ notes, as indicated by deposits at Federal Reserve Banks; this was close to (and, in a sense, better than) the 60.4 percent observed at the same point in the series-1990 introduction (better because it gives the Federal Reserve an opportunity to replace even more pre-1996 notes).

It does not seem overly optimistic to project that the circulation of series-1996 \$100 notes will reach 75 percent of worldwide \$100-note circulation and 85 percent of domestic circulation, ahead of the point at which those levels were achieved in the series1990 introduction - that is, in fewer than fifty-two months or by early in the year 2000 .

\section{SUMMARY}

In its choice of issuing strategies for the series-1996 $\$ 100$ note, the Federal Reserve was trying to balance the objectives of achieving a sufficiently rapid replacement of pre-1996 \$100 notes while imposing as little disruption as possible on the holders of those notes. The essential features of the strategy adopted are that (a) there is no recall of pre-series-1996 $\$ 100$ notes or any other requirement that the public exchange those notes and (b) pre-1996 $\$ 100$ notes are withdrawn as soon as they are deposited at Federal Reserve Banks and are replaced with new-design notes.

The outstanding $\$ 100$ notes are widely dispersed. Perhaps two-thirds of all $\$ 100$ notes are held outside the United States, chiefly by a great many households and small business firms in countries in which U.S. currency is viewed as preferable to the local currency for household saving and for many household and business transactions. The issuing strategy is minimizing inconvenience to these holders; a more aggressive strategy, in terms of inducing a faster return of old-design $\$ 100$ notes, could have been significantly disruptive to holders abroad, possibly even raising questions about the long-term desirability of using U.S. currency for saving and for business transactions. Neither the current counterfeiting situation nor the likely threat over the coming several years argues for causing significant inconvenience or disruption to the public in order to remove preseries-1996 \$100 notes from circulation.

As demonstrated in the introduction of the series$1990 \$ 100$ notes, the large volume of $\$ 100$ notes deposited by depository institutions at Federal Reserve Banks makes possible an extensive and relatively prompt replacement, at the Reserve Banks, of earlier-series $\$ 100$ notes with notes of the new series. By the year 2000, series-1996 \$100 notes may well compose 75 percent of worldwide $\$ 100$-note circulation and 85 percent of $\$ 100$-note circulation within the United States.

In view of these circumstances, the Federal Reserve's choice of issuing strategy appears likely to achieve its objectives: a replacement of pre-series$1996 \$ 100$ notes that is timely in relation to the developing threat of counterfeiting, with a minimum impact on holders and users of those notes throughout the world. 